\title{
Tay-Sachs disease heterozygote detection: use of a centrifugal analyser for automation of hexosaminidase assays with two different artificial substrates
}

\author{
Eleanor C Landels, Ian H Ellis, Martin Bobrow, Anthony H Fensom
}

\begin{abstract}
An assay for measuring hexosaminidase $A$ in serum and leucocytes is described in which a centrifugal analyser is used for automation of the enzyme assays after manual heat inactivation. The assay was used in a screening programme to identify heterozygotes for Tay-Sachs disease in Ashkenazi Jewish subjects in the UK. The first results from this programme indicate a carrier frequency of 1 in 27. Automation of an assay for direct measurement of hexosaminidase $A$ in serum using 4-methylumbelliferyl- $\beta-N$-acetylglucosamine-6-sulphate as substrate is also described. Comparison of data obtained from 66 control and 30 obligate carrier sera tested by this method and by heat inactivation showed improved discrimination using the sulphated substrate. Results obtained using the sulphated substrate for screening serum during pregnancy are also presented.
\end{abstract}

Tay-Sachs disease (TSD) is an incurable, neurodegenerative disorder of autosomal recessive inheritance, characterised in the classic form by progressive mental and motor weakness resulting in deafness, blindness, generalised paralysis, and death, usually by 4 years of age. ${ }^{1}$ The cause is a mutation at the locus encoding the $\alpha$ peptide of hexosaminidase $A$ (Hex A), the most biologically important isoenzyme of the lysosomal hexosaminidases. Affected homozygotes are deficient in Hex A so that the enzyme's

Paediatric Research Unit, Division of Medical and Molecular Genetics, United Medical and Dental Schools of Guy's and St Thomas's Hospitals, 8th Floor, Guy's Hospital Tower, London SE1 9RT.

E C Landels, I H Ellis, M Bobrow, A H Fensom Correspondence to Dr Fensom.

Received for publication 19 April 1990.

Revised version accepted for publication 31 July 1990. substrate, ganglioside $\mathrm{GM}_{2}$, is not degraded and accumulates in neuronal cells leading to the characteristic pathology of the disease.

Hex $A$ is composed of $\alpha$ and $\beta$ peptides. The other major isoenzymes, Hex $B, \operatorname{Hex} S$, and the intermediate hexosaminidases, are composed of various combinations of $\alpha$ and $\beta$ peptides. Mutation of the locus coding the $\beta$ peptide causes reduction in the activity of all hexosaminidases except Hex $S$ (which is composed of $\alpha$ peptides only). The resulting condition, Sandhoff's disease (SHD), is biochemically distinguishable from TSD but clinically similar.

Carriers of the TSD gene have reduced Hex A activity, ${ }^{2}$ and are approximately 10 times more frequent in the Ashkenazi Jewish community than in the general population. This led to the introduction of screening programmes in the early 1970 s to identify carriers. ${ }^{3}$ The method used for carrier testing in most laboratories involves determining the total Hex activity in serum, and the proportion of Hex activity which is heat labile under standardised conditions (predominantly Hex A) using the sensitive fluorogenic substrate 4-methylumbelliferyl- $\beta-D-N$-acetylglucosamine. The procedure can be automated using continuous flow equipment with two matched fluorimeters reading the product of the reaction of unheated and heated serum samples. ${ }^{4} \mathrm{~A}$ number of factors (pregnancy, inflammatory illnesses, oral contraceptive pill), which alter the proportion of Hex A relative to the other Hex isoenzymes in serum, can lead to false positive carrier identification. ${ }^{5} 6$ In these circumstances, assay of Hex A in leucocytes usually allows accurate classification of genotype.

Less empirical methods for assay of Hex A are based on use of 6-sulphated chromogenic ${ }^{7}$ or fluorogenic $^{89}$ substrates. Hex $\mathrm{A}$ is considerably more active towards these substrates than is Hex B, and recent work indicates that use of the substrates has advantage in classification of Tay-Sachs disease genotypes, including carrier detection. ${ }^{7-9}$

The recognition of a splice junction defect ${ }^{10}$ and a four base insertion ${ }^{11}$ in the Ashkenazi population, which together account for about $90 \%$ of the TSD 
mutations, provides an alternative method for confirming carrier status.

Data reported by the National Tay-Sachs and Allied Diseases Association in San Diego showed that by 1987639880 Ashkenazi subjects had been screened worldwide, and a carrier frequency of 1 in 25.6 was deduced. The great majority (over $99 \%$ ) of people screened were from the United States, Canada, Israel, and South Africa.

Efforts to introduce screening in the United Kingdom were made in 1972 but met with only limited success for reasons discussed by Evans. ${ }^{12}$ Recently, however, there has been renewed interest in carrier screening within the Ashkenazi population of the UK. In preparation for offering screening on a large scale we have assessed the use of the Cobas Bio centrifugal analyser (Roche Products Ltd), for automation of serum and leucocyte Hex A determinations, as an alternative to use of a continuous flow system.

The centrifugal analyser accurately pipettes sample and fluorescent substrate (and, after incubation, stop buffer), loading them into a rotor where they are mixed by centrifugal force. The incubation period of all samples begins and ends at the same time, after which the fluorescence is measured and converted to nmol 4-methylumbelliferone/ml by the microprocessor within the centrifugal analyser. Samples must be split and some aliquots heat inactivated in order to differentiate Hex $\mathrm{A}$ from the other isoenzymes before loading on to the centrifugal analyser. This is in contrast to the continuous flow system where serum samples are split after loading and heat inactivated in a heating coil within the machine.
We have compared results for obligate carriers of the TSD gene with those of a control group of nonJewish subjects in order to establish carrier and normal percentage Hex A ranges for sera and leucocyte samples. We describe the operation and evaluation of this system and report our data on the first 2965 Ashkenazi subjects to be screened. We also report data on the use in carrier screening of the substrate 4-methylumbelliferyl- $\beta-N$-acetylglucosamine6-sulphate and discuss the possibility of using serum as the sample for screening during pregancy in the light of results obtained with this substrate.

\section{Materials and methods \\ PREPARATION OF SAMPLES}

Serum (separated within 18 hours of being taken and stored at $-30^{\circ} \mathrm{C}$ ) was diluted $(1 / 10)$ in citratephosphate buffer $(12 \mathrm{mmol} / \mathrm{l}$ citric acid, $20 \mathrm{mmol} / \mathrm{l}$ $\mathrm{Na}_{2} \mathrm{HPO}_{4}, \mathrm{pH} \mathrm{4.4)}$. Leucocyte pellets were prepared from heparinised blood ( $5 \mathrm{ml}$ per pellet) within 18 hours (blood stored at $4^{\circ} \mathrm{C}$ ) of being taken, by the dextran sedimentation method, ${ }^{13}$ and stored at $-30^{\circ} \mathrm{C}$. Each pellet was resuspended in 0.8 to $1.0 \mathrm{ml}$ deionised water and disrupted by sonication $(3 \times 10$ second bursts, MSE 150W instrument with microprobe, amplitude 3, separated by 10 seconds cooling in an ice bath). The sonicate was centrifuged $(200 \mathrm{~g}$ for 10 minutes at $4^{\circ} \mathrm{C}$ ) and the supernatant protein concentration assayed by the method of Lowry et $a^{14}$ using the centrifugal analyser (with parameters set as in the table, column B). The sonicate supernatant was adjusted with deionised water to 1.0 to $1.5 \mathrm{mg}$

Parameter settings for assays performed with the Cobas Bio centrifugal analyser.

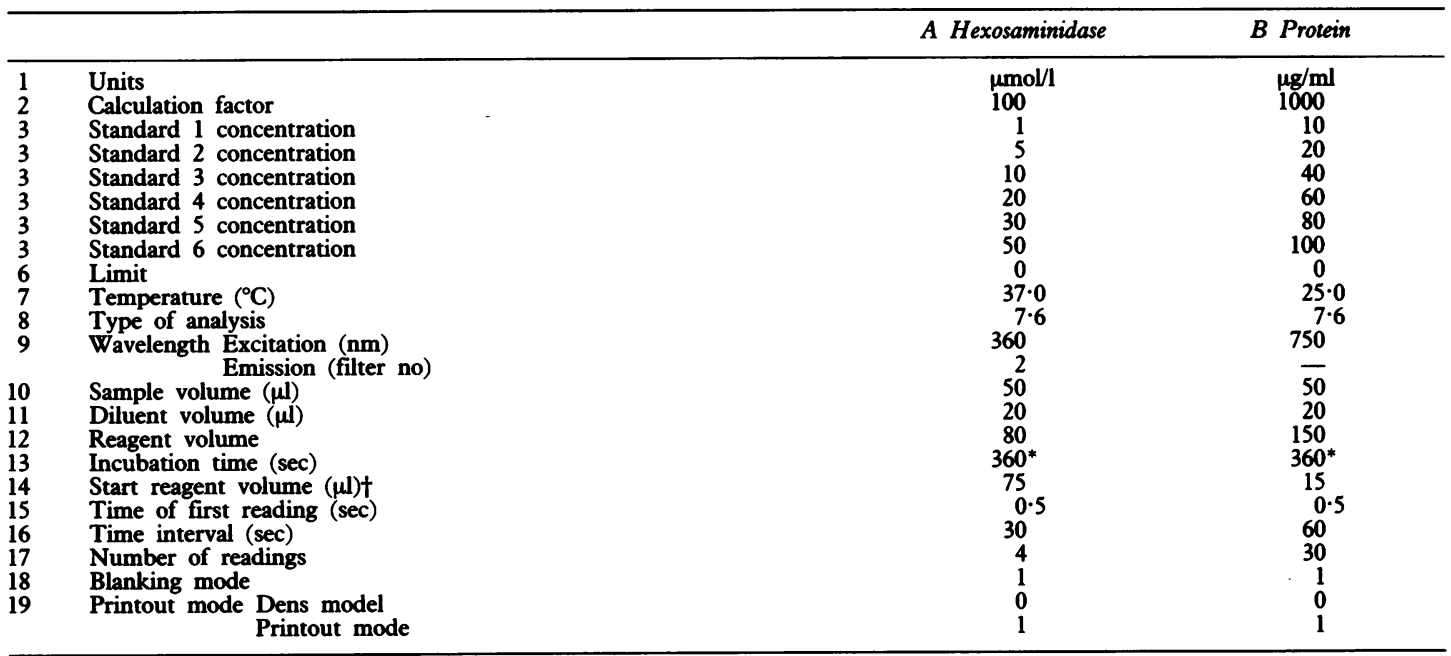

*In the 'substrate start' mode of analysis, a full rotor of specimens is incubated for an additional four minutes after the set incubation time while glycine buffer (for hexosaminidase) or Folin reagent (for protein) is added to the sample cavities of the cuvette rotor. tStrictly, stop reagent for hexosaminidase. 
protein/ml and diluted $(1 / 10)$ in $0.75 \%$ human serum albumin in citrate-phosphate buffer, as above.

\section{MANUAL HEXOSAMINIDASE ASSAY}

The method was based on the heat inactivation procedure of Kaback, ${ }^{15}$ the main difference being that inactivation was carried out for three hours at $50^{\circ} \mathrm{C}$ instead of two and three hours at $52^{\circ} \mathrm{C}$, and the enzyme reaction was run for $\mathbf{6 0}$ minutes instead of $\mathbf{3 0}$ minutes. The reaction was stopped with $0.5 \mathrm{~mol} / \mathrm{l}$ glycine- $\mathrm{NaOH}$ buffer, $\mathrm{pH} 10.3(3 \mathrm{ml})$ and fluoresence read using a Perkin Elmer LS2B fluorimeter $(366 \mathrm{~nm}$ filter, emission wavelength $448 \mathrm{~nm}$ ).

\section{AUTOMATED HEXOSAMINIDASE ASSAY FOR SERA AND LEUCOCYTES}

In developing the automated assay for Hex A we attempted to reproduce as far as possible the conditions of our manual assay. The diluted sera or leucocyte sonicates were aliquoted into four analyser sample cups; two aliquots were heated at $50^{\circ} \mathrm{C}$ for three hours to inactivate Hex $A$ while the other aliquots remained at $0^{\circ} \mathrm{C}$ in an ice bath.

All four aliquots were then assayed using the centrifugal analyser with the parameters set as shown in the table, column A (substrate start mode; nonlinear chemistry). The concentration of the substratebuffer reagent was $3.75 \mathrm{mmo} / \mathrm{/}$ 4-methylumbelliferyl$\beta-D-N$-acetylglucosamine (Sigma, St Louis) in 25 $\mathrm{mmol} / 1 \mathrm{Na}_{2} \mathrm{HPO}_{4}-15 \mathrm{mmol} / \mathrm{l}$ citric acid, $\mathrm{pH} \mathrm{4.4}$. The stopping reagent was $0.5 \mathrm{~mol} / \mathrm{l}$ glycine- $\mathrm{NaOH}, \mathrm{pH}$ 10.3. Standard solutions of 4-methylumbelliferone (Koch-Light, Colnbrook) in water at the indicated concentrations (table) were used for daily calibration of the instrument. Time of incubation at $37^{\circ} \mathrm{C}$ was usually 10 minutes for both serum and leucocytes, but was increased to 20 minutes for low activity specimens. The Hex activity of the heat inactivated aliquots was compared with those kept on ice and the difference used to calculate the percentage Hex $A$ for each sample. Known normal and heterozygote samples were assayed daily for quality control.

\section{AUTOMATED HEXOSAMINIDASE ASSAY USING THE \\ 6-SULPHATED SUBSTRATE FOR SERA}

Serum hexosaminidase activity towards the substrate 4-methylumbelliferyl- $\beta-D-N$-acetylglucosamine-6-sulphate (4MUGS) (HSC Research Development Corporation, Toronto) was assayed using the centrifugal analyser with the parameter settings shown in the table, column A, except that standard 4-methylumbelliferone concentrations were $0 \cdot 1,0.5,1 \cdot 0,5 \cdot 0$, 10.0 , and $20.0 \mu \mathrm{mol} / \mathrm{l}$. The concentration of the substrate-buffer reagent was $3.75 \mathrm{mmol} / 4$ MUGS in
$25 \mathrm{mmol} / \mathrm{Na}_{2} \mathrm{HPO}_{4}-15 \mathrm{mmol} / \mathrm{l}$ citric acid, $\mathrm{pH} \mathrm{4} 4$, and the incubation time was 20 minutes. Serum was diluted 1 in 10 with $12 \mathrm{mmol} / 1$ citrate- $20 \mathrm{mmol} / \mathrm{l}$ phosphate buffer for these tests which enabled assays with sulphated and unsulphated substrates to be carried out with the same diluted samples.

\section{Results}

PRELIMINARY ASSESSMENT OF THE CENTRIFUGAL ANALYSER FOR HEX DETERMINATION

In developing the automated assay for hexosaminidase A the main change necessary was reduction of volume of stopping buffer from $3 \mathrm{ml}$ in the manual assay to $75 \mu \mathrm{l}$. This was dictated by the pipetting procedure and rotor cuvette size of the centrifugal analyser. In order to assess the effectiveness of the smaller volume of buffer for stopping the enzyme reaction, the analyser was set to read the fluorescence of the product of the reaction of heated and unheated normal and heterozygous sera over a 10 minute period at 30 second intervals after addition of the glycine. Results showed that fluorescence slowly increased over this time by about $1 \%$ of the initial reading. It was concluded that during the 90 second reading period of the standard assay the increase would not be sufficient to introduce a significant error into the results.

The calibration of the analyser with different concentrations of 4-methylumbelliferone was found to be linear over the range studied $(0.204$ to $10.2 \mu \mathrm{mol} / \mathrm{l}$ final concentration).

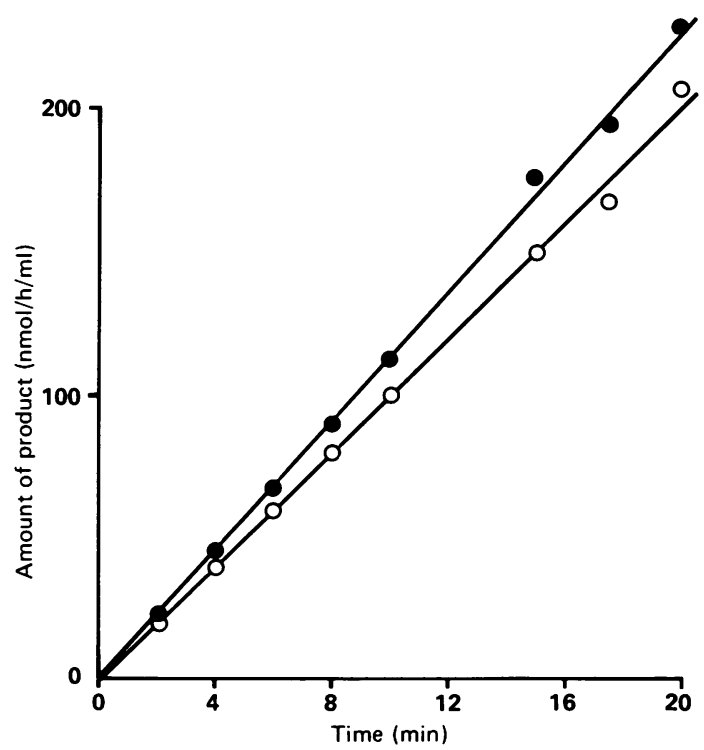

Figure 1 Effect of incubation time on total Hex activity measured in two normal sera using the centrifugal analyser. 
The rate of reaction was found to be constant for both normal serum (fig 1) and normal leucocyte extracts (fig 2) over the time studied (two to 20 minutes). Activity in normal leucocyte extracts was proportional to the protein concentration over the range 0.2 to $3.0 \mathrm{mg} / \mathrm{ml}$, equivalent to 1 to $15 \mu \mathrm{g}$ in the incubation mixture (fig 3).

DIRECT COMPARISON OF MANUAL AND AUTOMATED ASSAYS Dilutions of 147 sera and 106 leucocyte specimens from subjects with a wide range of percentage Hex A ( 5 to $80 \%$ ) were assayed simultaneously by the manual and automated methods, and the results for the percentages of Hex A recorded were analysed as described by Bland and Altman. ${ }^{16}$ The comparison showed that the automated method gave slightly higher values than the manual method for both types of specimen, the mean difference between paired results being 0.8 percentage points for leucocytes and 3.2 percentage points for serum.

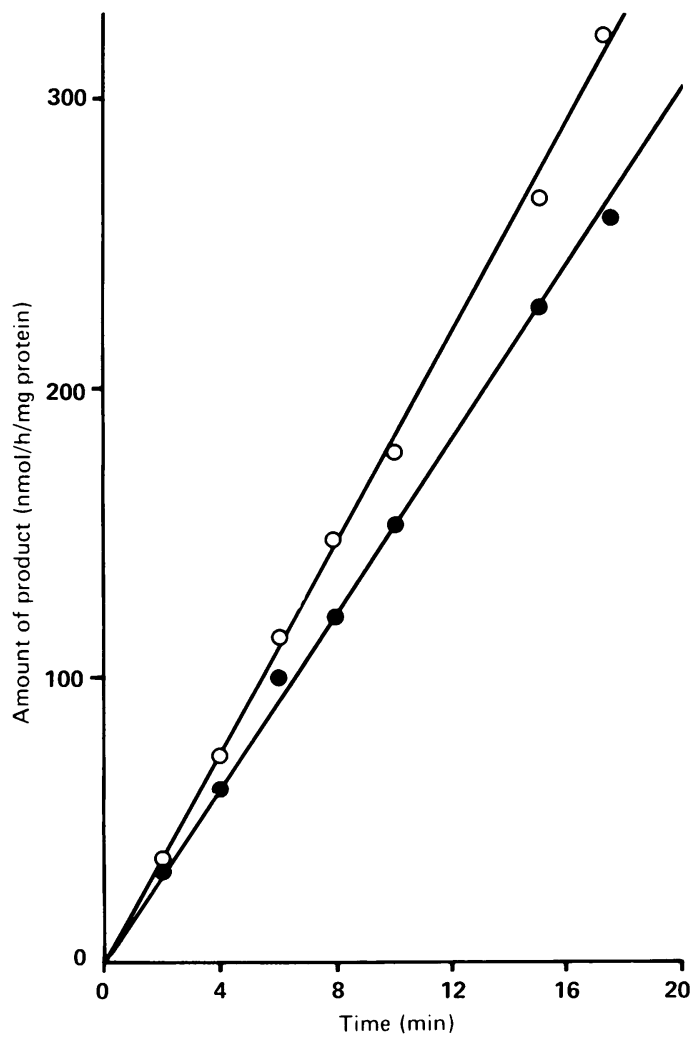

Figure 2 Effect of incubation time on total Hex activity measured in two normal leucocyte extracts using the centrifugal analyser.

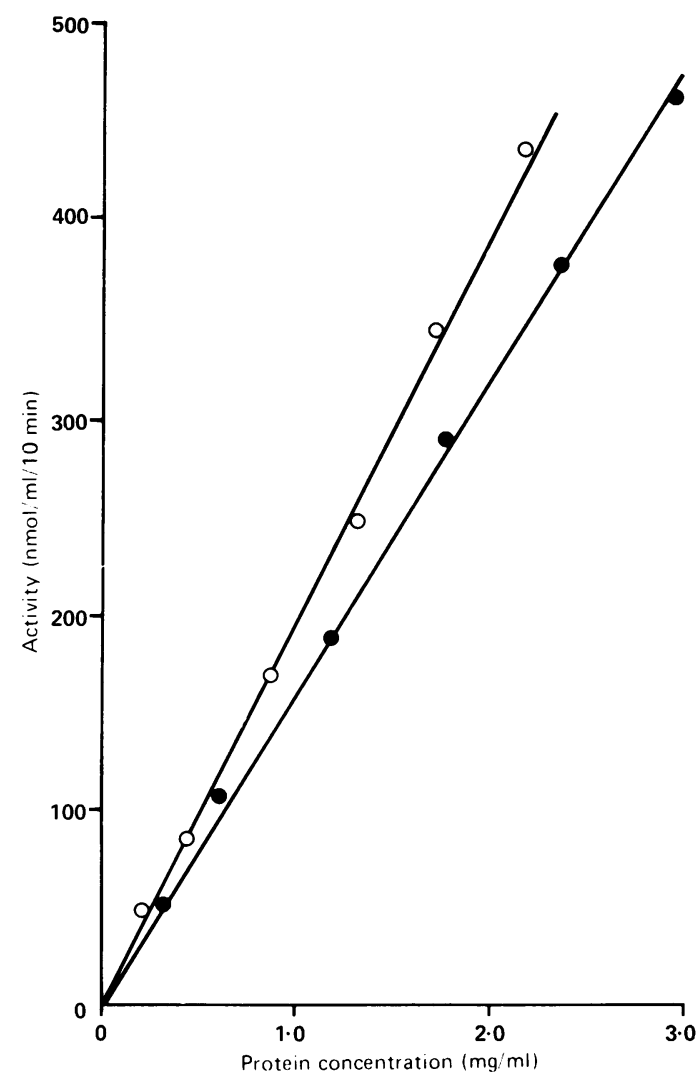

Figure 3 Effect of protein concentration on total Hex activity measured in two normal leucocyte extracts using the centrifugal analyser.

HEX A IN SERA (HEAT INACTIVATION METHOD, UNSULPHATED SUBSTRATE)

Results obtained for a control group of 66 non-Jewish blood donors, 30 obligate carriers of TSD, four of SHD, and two affected TSD patients are shown in fig 4. The data are presented as a two dimensional plot of Hex A activity versus percentage Hex A. The highest value for percentage Hex A recorded for an obligate TSD carrier was $58 \%$. For screening purposes, subjects with values of 55 to $59 \%$ were classified initially as inconclusive, and those with values of 35 to $54 \%$ as probable carriers. Both groups were followed up with a leucocyte assay. The serum results of two of the control group (numbered 1 and 2) fell near to the obligate carrier range.

HEX A IN LEUCOCYTES (HEAT INACTIVATION METHOD, UNSULPHATED SUBSTRATE)

The percentage Hex $A$ in leucocytes for a control group of 49 non-Jewish subjects and 30 obligate TSD 


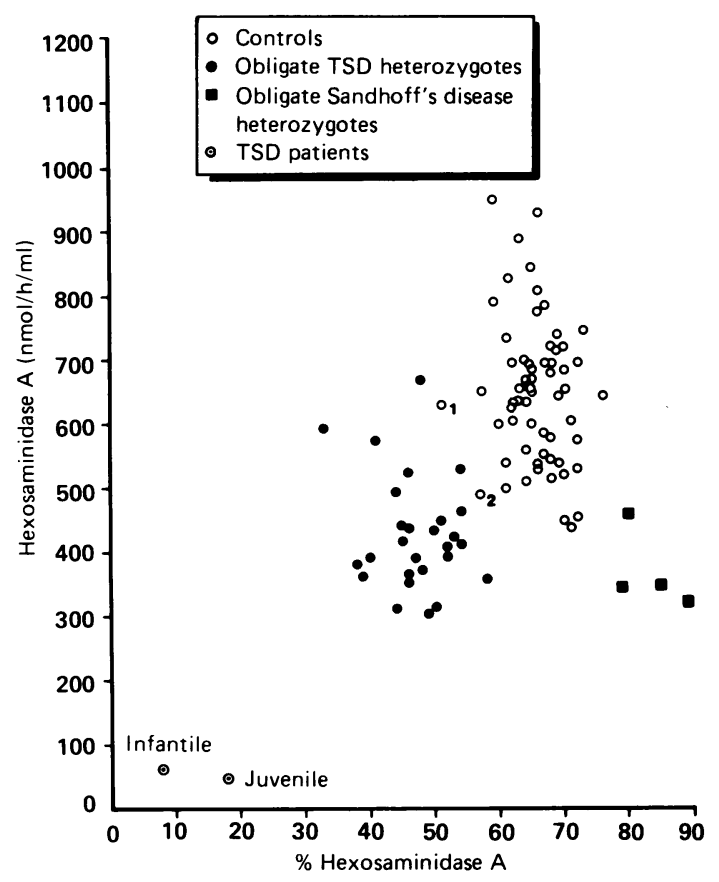

Figure 4 Two dimensional plot of Hex A (measured by the heat inactivation method) versus percentage Hex $A$ in serum from controls, obligate TSD heterozygotes, obligate Sandhoff s disease heterozygotes, and TSD patients.

carriers is shown in fig 5. From these data a cut off point of $59 \%$ between carriers and non-carriers was taken, although the value for one control was $55 \%$. The results of screening 268 Jewish subjects (mainly pregnant women or those with inconclusive or carrier serum results) and 28 subjects with a family history of TSD yielded the distribution shown in fig 6 . The overall carrier frequency found, based on screening 2965 subjects using serum, leucocytes, or both specimens, was 1 in 27.
HEX A IN SERA (SULPHATED SUBSTRATE)

A clear discrimination between obligate TSD carriers and the non-Jewish control group was obtained when Hex A activity (measured with the sulphated substrate) was plotted against Hex A (measured with the sulphated substrate) as a fraction of the total Hex activity (measured with the unsulphated substrate using the centrifugal analyser) (fig 7). There was no clear discrimination if Hex A activity alone was considered. The same two control subjects who gave inconclusive results when tested by heat inactivation appeared near to the carrier group using the sulphated substrate (they are numbered as in fig 4). SHD carriers were not readily identified using the sulphated substrate. It should be noted that the rate of hydrolysis of the sulphated substrate by Hex A is lower than the rate with the unsulphated substrate, and that units on the abscissae of figs 4 and 7 are therefore not directly comparable.

\section{HEX A IN SERA TAKEN DURING PREGNANCY}

Hex A activity is plotted against gestational age in fig 8 (Hex A measured by heat inactivation) and fig 9 (Hex A measured with the sulphated substrate). All subjects shown had been assigned carrier status using the leucocyte assay. The sulphated substrate gave clear discrimination between carriers and non-carriers, whereas there was overlap of the two groups when Hex A was measured by heat inactivation.

\section{Discussion}

The results presented here show that the heat inactivation method for determining Hex A in both sera and leucocytes is readily adaptable to a centrifugal analyser. Although not a completely automated procedure (the heat inactivation step is manual), the method has the advantage over a continuous flow system in not requiring dual fluorescence readings and careful balancing of instruments. Moreover, the ability to use the analyser to test leucocytes as well as

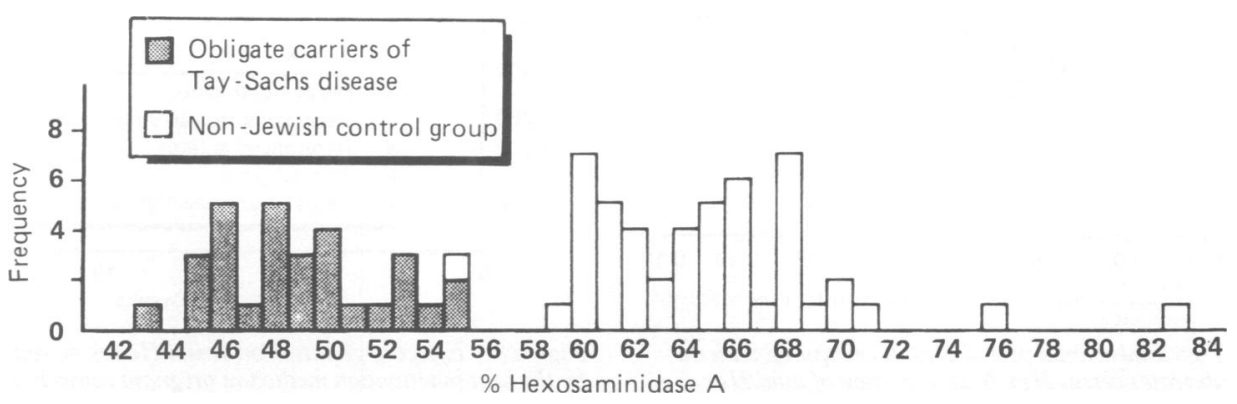

Figure 5 The percentage Hex A recorded in leucocyte extracts from controls and obligate TSD carriers. 


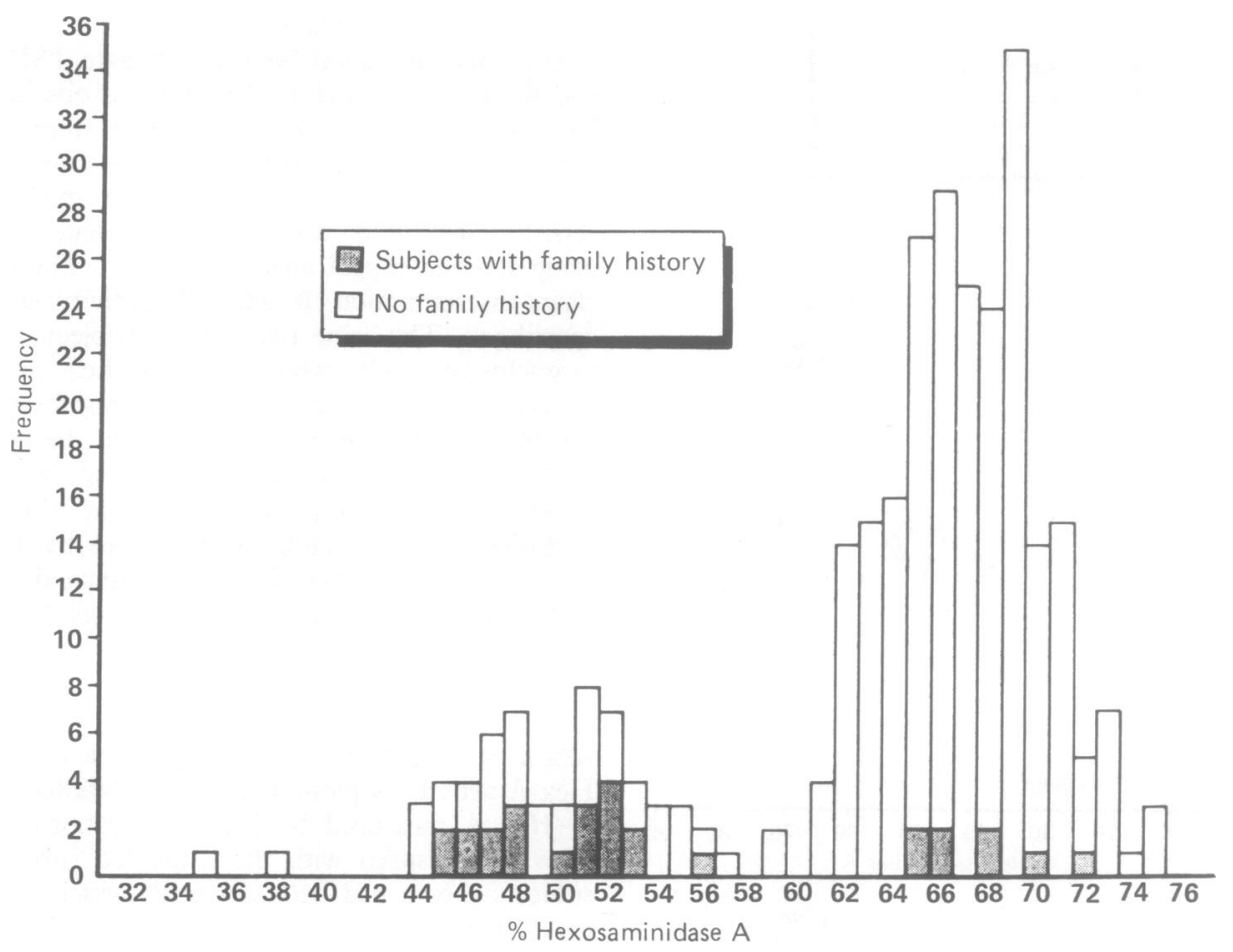

Figure 6 The percentage Hex A recorded in leucocyte extracts from screened subjects.

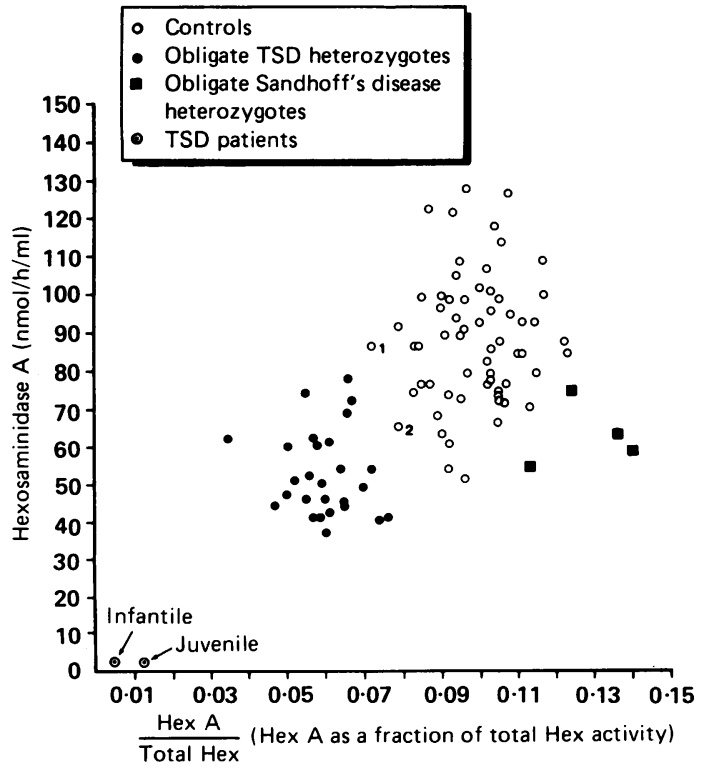

Figure 7 Two dimensional plot of $\mathrm{Hex} A$ (measured with the sulphated substrate) versus $H$ ex $A$ as a fraction of total $H e x$ activity in serum from controls, obligate TSD heterozygotes, obligate Sandhoff s disease heterozygotes, and TSD patients.

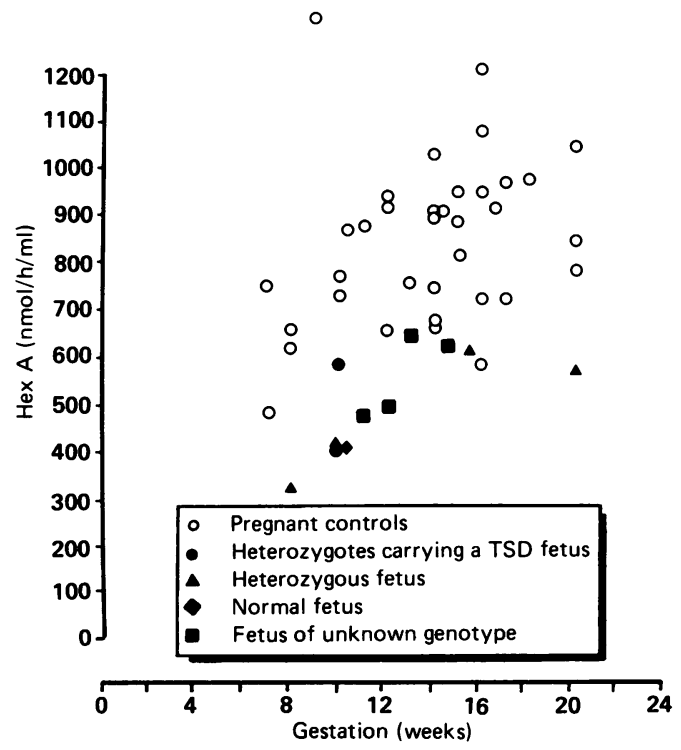

Figure 8 Effect of gestation on serum Hex $A$ activity measured by the heat inactivation method in pregnant controls and heterozygotes carrying a TSD fetus, a heterozygous fetus, a normal fetus, or a fetus of unknown genotype. 


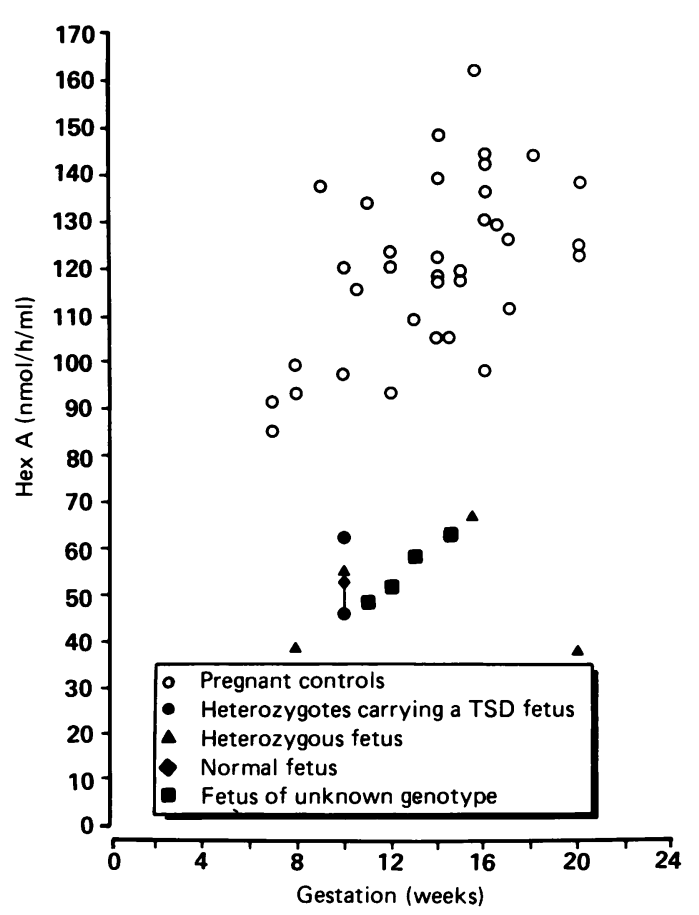

Figure 9 Effect of gestation on serum Hex A activity measured with the sulphated substrate in pregnant controls and heterozygotes carrying a TSD fetus, a heterozygous fetus, $a$ normal fetus, or a fetus of unknown genotype. The joined points represent subsequent pregnancies in the same mother.

serum with the same assay conditions is a particular advantage. Plasma cannot be used for the assay because the precipitation which occurs when plasma is diluted with the citrate-phosphate buffer leads to inaccurate pick up of sample by the sampling needle. However, plasma is not usually used for Tay-Sachs screening because Hex activity is lower in this fluid than in serum, so this is not a serious disadvantage. We observed that some serum samples which had been stored frozen for many months gave unreliable results; we attributed this to the greater tendency which these samples had to form some protein precipitate on thawing for assay, again leading to inaccuracies in sample pick up. This meant that we could not use aged specimens from controls and obligate heterozygotes for establishing our reference ranges, and all specimens had to be freshly obtained. It was not a serious disadvantage for routine screening because these specimens were always processed within three weeks of receipt.

For day to day quality control of the assays, an aliquoted sample of serum or a leucocyte pellet from a normal control and an obligate TSD heterozygote (stored at $-70^{\circ} \mathrm{C}$ ) were included with each batch of test specimens. The values obtained for these samples usually varied by \pm 3 percentage points between runs (for example, 44 to $49 \%$ Hex A for the heterozygous serum). If a value outside these limits was obtained in any run, the data for that run were rejected and the whole batch of specimens was reanalysed.

A study in which leucocytes and serum from normal subjects, TSD and Sandhoff's disease heterozygotes, and TSD patients were assayed simultaneously using our standard manual method and the automated method showed that the mean difference ${ }^{16}$ between results was only 0.8 percentage points for analysis of leucocytes and $3 \cdot 2$ percentage points for serum. The automated method gave results for serum which were, on average, 3.2 percentage points higher than those given by the manual method, but the discrimination between normal, heterozygous, and TSD affected groups was not compromised. The $3 \cdot 2$ percentage points difference between manual and automated methods found with serum may have been because of slight colour quenching occurring when fluorescence of samples was read in smaller volumes. The effect would not be expected with colourless leucocyte samples.

Although our screening programme was based on taking the value for percentage Hex $A$ in serum as the primary indicator of genotype, the sera data were examined as a two dimensional plot of Hex A activity versus percentage $H$ ex $A$ in an attempt to reduce misclassification (fig 4). This approach has been discussed by Gold, ${ }^{17}$ who presented data for serum hexosaminidase as a two dimensional plot of Hex A versus Hex B. We found the approach to be useful in assessing genotype in borderline subjects (55 to $59 \%$ Hex $A$ in serum) before the leucocyte assay was completed, but in practice always retested using leucocytes. This involved recalling about 3\% of subjects initially screened using serum.

The carrier frequency found for the UK Ashkenazi population ( 1 in 27 based on 2965 subjects screened) compares with that reported elsewhere (for example, 1 in 31 in a North American Jewish population ${ }^{1}$ ).

The assay for Hex A in serum using the sulphated substrate can also be readily automated. Measurement of Hex A activity alone was found to give poor discrimination between carriers and non-carriers, but when plotted against Hex $A$ as a fraction of total Hex (measured with the centrifugal analyser and the unsulphated substrate) good discrimination was obtained (fig 7). This assay has the advantage of avoiding the heat inactivation step and may also detect carriers of the rare TSD Bl variant who have normal Hex $A$ activity when measured by the heat inactivation method. ${ }^{18} 19$ A careful comparison of figs 4 and 7 shows that the two discriminant test with the sulphated substrate gives better separation between carriers and normal subjects than the test based on heat inactivation. Bayleran $e t a l^{8}$ also found this to be the case, using manual assays and analysing their data to transform 
Hex A results obtained with the sulphated substrate to equivalent units to those obtained with the unsulphated substrate. However, these workers, and also Ben-Yoseph et al, ${ }^{9}$ obtained good separation between controls (37 and 33 studied in each series, respectively) and carriers (19 studied in both series) using serum Hex A activity as a single discriminant. In contrast, we found that with our larger groups of 66 controls and 30 carriers (and using slightly different assay conditions) poor separation of genotypes was obtained by measuring activity towards the sulphated substrate alone.

Screening of pregnant women poses particular problems since during pregnancy the serum activity of heat stable intermediate Hex isoenzymes increases, thus reducing the relative activity of $\mathrm{Hex} A$ and leading to a falsely low percentage Hex A. ${ }^{5}$ In an attempt to overcome this problem we assayed absolute activity of Hex A in serum from pregnant carriers and non-carriers using both the heat inactivation method and the sulphated substrate.

There was no discrimination between pregnant carriers and pregnant non-carriers when Hex $\mathrm{A}$ in serum samples was measured by heat inactivation (fig 8). However, discrimination was improved in the group of patients studied when Hex A was measured with the sulphated substrate (fig 9). In using the heat inactivation method it is assumed that only Hex A is thermolabile, but other hexosaminidases may also be thermolabile to a small degree, ${ }^{20}$ and this will lead to errors in Hex A determination. On the other hand, measurement of Hex A activity with the sulphated substrate relies on its specificity for this substrate, and errors will be introduced if any hydrolysis by other isoenzymes occurs. On balance, since our studies (Fensom and Landels, unpublished data) show that Hex B and Hex I separated by FPLC have negligible activity towards the sulphated substrate, it is likely that the slight thermolability of other isoenzymes introduces more error than non-specific hydrolysis of the sulphated substrate, thus explaining the better discrimination obtained with the sulphated substrate.

In addition to problems caused during pregnancy by an increase in Hex I, a further complication arises from increase in Hex A itself. This increase is probably the result of transfer of fetal Hex $A$ to the mother. Navon $e t a^{21}$ showed that serum Hex A remained unchanged during the second trimester in three pregnant obligate carriers for TSD who carried affected fetuses, whereas it increased four-fold in two pregnant mothers affected with adult onset $\mathbf{G M}_{2}$ gangliosidosis who carried unaffected fetuses. This complication is likely to reduce the usefulness of measurement of Hex A in serum with the sulphated substrate for carrier detection at later gestational times; however, our results in sera taken earlier during pregnancy are encouraging (fig 9). In the case of one obligate carrier, serum was sampled during two pregnancies, one where the fetus was affected with TSD, and the other where the fetus was a non-carrier. Both sera were taken at 10 weeks' gestation; the Hex A levels are very similar (see fig 7; the two points are joined). Thus, at 10 weeks' gestation, the fetal contribution to maternal serum of Hex A appears to be very small, and even when the fetus is a non-carrier should not cause the maternal serum Hex A level of carriers to approach the non-carrier range. These results, though encouraging, are preliminary; at any gestation it remains prudent to confirm carrier status with the more reliable leucocyte assay.

We thank the British Tay-Sachs Foundation for generous financial support, Mrs Debbie Seedburgh and Mrs Zahavah Heckscher for secretarial and community screening assistance, and Miss Adrienne Knight for preparation of the manuscript. Dr M McLaren (Roche Diagnostics) provided useful advice in adapting our methods to the centrifugal analyser. The work of the Paediatric Research Unit is supported by the Spastics Society and the Generation Trust.

1 Sandhoff K, Conzelmann E, Neufeld EF, Kaback MM, Suzuki K. The $\mathrm{GM}_{2}$ gangliosidoses. In: Scriver CR, Beaudet AL, Sly WS, Valle D, eds. The metabolic basis of inherited disease. 6th ed. New York: McGraw-Hill, 1989:1807-39.

2 O'Brien JS, Okada S, Chen A, Fillerup DL. Tay-Sachs disease: detection of heterozygotes and homozygotes by serum hexosaminidase assay. $N$ Engl f Med 1970;283:15-20.

3 Kaback MM, Zeiger RS. Heterozygote detection in Tay-Sachs disease: a prototype community screening programme for the prevention of recessive genetic disorders. Adv Exp Biol Med 1972;19:613-32.

4 Kaback MM, Bailin G, Hirsch P, Roy C. Automated thermal fractionation of serum hexosaminidase: effect of alteration in reaction variables and implication for Tay-Sachs heterozygote screening. In: Kaback MM, ed. Tay-Sachs disease: screening and prevention. New York: Alan R Liss, 1977:197-212.

5 Stirling JL. Separation and characterisation of $\mathrm{N}$-acetyl- $\beta$-glucosaminidases A and P from maternal serum. Biochim Biophys Acta 1972;271:154-62.

6 Lowden JA, Zuker S, Wilensky AJ, Skomorowski MA. Screening for carriers of Tay-Sachs disease: a community project. Can Med Assoc f 1974;111:229-33.

7 Fuchs W, Navon R, Kaback MM, Kresse H. Tay-Sachs disease: one-step assay of $\beta-\mathrm{N}$-acetylhexosaminidase in serum with a sulfated chromogenic substrate. Clin Chim Acta 1983;133: 253-61.

8 Bayleran J, Hechtman P, Saray W. Synthesis of 4-methylumbelliferyl- $\beta-D-N$-acetylglucosamine-6-sulfate and its use in classification of $\mathrm{GM}_{2}$ gangliosidosis genotypes. Clin Chim Acta 1984;143:73-89.

9 Ben-Yoseph Y, Reid JE, Shapiro B, Nadler H. Diagnosis and carrier detection of Tay-Sachs diseases: direct determination of hexosaminidase $\mathbf{A}$ using 4-methylumbelliferyl derivatives of $\beta$ $\mathrm{N}$-acetylglucosamine-6-sulfate and $\beta$ - $\mathrm{N}$-acetylgalactosamine-6sulfate. Am F Hum Genet 1985;37:733-48.

10 Arpaia E, Dumbrille-Ross A, Maler T, et al. Identification of an altered splice site in Ashkenazi Tay-Sachs disease. Nature 1988;333:85-6.

11 Myerowitz R, Costigan FC. The major defect in Ashkenazi Jews with Tay-Sachs disease is an insertion in the gene for the $\alpha$ chain of $\beta$-hexosaminidase. $\mathcal{F}$ Biol Chem 1988;263:18587-9.

12 Evans P. Tay-Sachs screening in Britain. In: Kaback MM, ed. Tay-Sachs disease: screening and prevention. New York: Alan R Liss, 1977:55-9.

13 Dulaney JT, Moser HW. Sulphatide lipidosis: metachromatic 
leucodystrophy. In: Stanbury JB, Wyngaarden JB, Frederickson DS, eds. The metabolic basis of inherited disease. 4th ed. New York: McGraw-Hill, 1978:770-809.

14 Lowry OH, Rosebrough NJ, Farr AL, Randall RJ. Protein measurement with the Folin phenol reagent. $\mathcal{f}$ Biol Chem 1951;193:265-75.

15 Kaback MM. Thermal fractionation of serum hexosaminidases: applications to heterozygote detection and diagnosis of TaySachs disease. In: Ginsberg V, ed. Methods in enzymology. Vol XXVIII. New York: Academic Press, 1972:862-7.

16 Bland JM, Altman DG. Statistical methods for assessing agreement between two methods of clinical measurement. Lancet 1986;i:307-10.

17 Gold R. Genetic screening: how to use the data. In: Callahan JW, Lowden JA, eds. Lysosomes and lysosomal storage diseases. New York: Raven Press, 1981:357-71.
18 Charrow J, Inui $\mathrm{K}$, Wenger D. Late onset $\mathbf{G M}_{2}$-gangliosidosis: an $\alpha$-locus genetic compound with near normal hexosaminidase activity. Clin Genet 1985;27:78-84.

19 Besley GTN, Broadhead DM, Young JA. Diagnosis of hexosaminidase A deficiency with sulphated substrate: evidence for an alpha-locus genetic compound in a Tay-Sachs variant. In: Salvayre R, Douste-Blazy L, Gatt S, eds. Lipid storage disorders: biological and medical aspects. New York: Plenum Press, 1988:247-52.

20 Dance N, Price RG, Robinson D, Stirling JL. $\beta$-galactosidase, $\beta$ glucosidase and $\mathbf{N}$-acetyl- $\beta$-glucosaminidase in human kidney. Clin Chim Acta 1969;24:189-97.

21 Navon R, Lejbkowicz I, Adam A. Fetal hexosaminidase A in mother's serum: pitfalls for carrier detection and prospects for prenatal diagnosis of $\mathrm{GM}_{2}$-gangliosidoses. Am $\mathcal{F} \mathrm{Hum}$ Genet 1987;40:60-1. 